\title{
Investigation of Serum Pregnancy-Specific Beta-1-Glycoprotein and Relationship with Fetal Growth Restriction
}

\author{
Sabiha Tuzluoğlư ${ }^{1}$, Emin Üstünyurt ${ }^{1}$, Süleyman Serkan Karaşinn ${ }^{1}$, Zeynep Toksoy Karaşin ${ }^{1}$ \\ ${ }^{1}$ Obstetrics and Gynecology, Health Sciences University Bursa Yüksek İhtisas Training and Research Hospital, \\ Bursa, Turkey
}

\begin{abstract}
Objective: The most used definition for fetal growth restriction (FGR) is a fetus whose estimated weight is below the $10^{\text {th }}$ percentile for its gestational age. Pregnancy-specific beta-1-glycoprotein (PSG-1) is an immunomodulator found in maternal serum during pregnancy. This study aimed to determine the serum levels of PSG-1 and clarify the potential role of this molecule in the etiopathogenesis of FGR.

Methods: Eighty women carrying fetuses with FGR and 80 healthy pregnant women were included in the study. Demographic data, laboratory values, and Doppler Ultrasonography (USG) results of all cases were recorded. Venous blood samples were taken from all cases before birth. PSG-1 values were studied by the ELISA method. An Independent Samples T-test was used to evaluate the results. The correlations between parameters were evaluated based on Spearman's rank correlation coefficient. $P$-values $<0.05$ were considered statistically significant.

Results: When the groups were evaluated for serum PSG-1 levels, the median serum PSG-1 level was lower in pregnant women carrying fetuses with FGR than in controls $(0.05<p>0.10)$. Median serum PSG- 1 was lower in patients with absent end diastolic flow (AEDF) in the umbilical artery in Doppler ultrasound scans than in patients without AEDF, but the difference was not statistically significant $(p>0.05)$. In patients with serum PSG-1 values below 12.93 with $50 \%$ sensitivity and $76 \%$ specificity, the risk of FGR was higher.
\end{abstract}

Conclusions: Serum PSG-1 levels may be lower in complicated pregnancies due to problems related to placental insufficiency and FGR.

Keywords: fetal growth restriction, serum beta 1 glycoprotein, pregnancy

\section{INTRODUCTION}

Fetal growth restriction (FGR) is defined as a fetus with an estimated weight below the 10th percentile for its gestational age (Dubinsky \& Sonneborn, 2020; Clausson et al., 2001). Although FGR is a complication seen in $5-10 \%$ of all pregnancies, the perinatal period after a preterm birth is a time of increased mortality and morbidity in childhood (Say et al., 2003; Resnik, 2002).

Neonatal outcomes of FGR include perinatal asphyxia and neonatal adaptive problems, and short- and longterm sequelae. In infants with FGR, the perinatal mortality rate is $10-20$ times greater than the rate observed in healthy fetuses (Barker, 1999). Perinatal mortality and morbidity can decrease by correct diagnosis, appropriate surveillance, and timely intervention. Since successful intrauterine treatment has not been defined for fetuses with FGR, planning delivery for the most appropriate time is essential in antenatal management. In timing birth, the aim is to ensure that maximum gestational age is reached and the risks to intrauterine life are minimized (Clausson et al., 2001; Soothill et al., 1987). Pregnancies with fetal growth retardation are of high risk and may become a public health problem due to poor fetal and neonatal outcomes. It is essential to identify and adequately follow fetuses with FGR, since this complication negatively affects perinatal outcomes in terms of mortality and morbidity. For this reason, many studies have been conducted for diagnostic purposes. However, to date, no useful biochemical marker or endocrine test has been found to monitor fetal growth or predict growth retardation healthily.

Maintenance of intrauterine development is possible with adequate oxygen and nutritional support. This condition happens with the continual change and development of uteroplacental circulation throughout pregnancy (Macara et al., 1996)though an alternative explanation is that the placenta fails to adequately transfer oxygen to the fetus from the intervillous space. Because oxygen transport takes place within the terminal villi, we undertook the first detailed studies of villous ultrastructure structure and immunohistochemistry in order to determine the likely origin of fetal hypoxia in this condition. Terminal villi were examined ultrastructurally using transmission electron microscopy and by immunohistochemical localization of matrix molecules (laminin and collagens I, III and IV. The placenta provides nutritional and respiratory support for the maintenance of fetal life. Therefore, disorders in placental structure and function are responsible for FGR (Salafia et al., 1995). Molecules that effectively ensure uteroplacental circulation are thought to contribute to fetal development. Many published studies have looked into this concept. However, none found diagnostic markers of FGR or described its pathophysiology clearly.

Pregnancy-specific beta-1-glycoprotein (PSG-1) is a protein subgroup recently isolated from human placenta and maternal serum (Grudzinskas et al., 1983; Tatarinov \& Masiukevich, 1970) Bohn found that PSG was immunologically similar to Schwangerschafts protein 1 (SP1), which the author had isolated from human placenta (Bohn, 1971; Chou \& Plouzek, 1992). Serum PSG-1 levels were used to diagnose pregnancy and pregnancy-related complications (Chou \& Plouzek, 1992; Tamsen et al., 1983). During pregnancy, PSG-1 becomes detectable in maternal serum 10 to 18 days after the ovulatory luteinizing hormone surge. It increases as pregnancy progresses and doubles within 2.4 days and achieves a very high level of $200-400 \mu \mathrm{g} / \mathrm{ml}$ at term (Lee et al., 1979; Lenton et al., 1981). Besides, PSG-1 is used as a marker for malignant disease and in the monitoring of choriocarcinoma therapy (Tatarinov \& Masiukevich, 1970). Molecular studies also revealed the substantial similarity of human PSG species with carcinoembryonic antigen (CEA) members. Carcinoembryonic antigen is a widely used marker for colonic cancers (Shively \& Beatty, 1985).

Pregnant women were through to secrete serum pregnancy-specific beta-1-glycoprotein (PSG-1). It is the most released fetal protein from placental syncytiotrophoblasts 
to the maternal circulation during late pregnancy (Zhou et al., 1997). Studies focused mostly on the effect of this molecule on the regulation of the maternal immune system.

This study aims to compare the serum concentrations of PSG-1 seen in healthy pregnant women and in pregnant women carrying fetuses with growth restriction, and to identify patients at risk of FGR by assessing the relationship between this molecule and pregnancies complicated by intrauterine growth retardation. The goal is to contribute to the adoption of strict control and follow-up measures to ultimately decrease fetal and maternal mortality and morbidity caused by FGR.

\section{MATERIAL AND METHODS}

This cross-sectional study was conducted in the Gynecology and Obstetrics Department of the Bursa Yüksek İhtisas Training and Research Hospital between March 2018 and December 2018. It included 160 volunteers, of which 80 were patients diagnosed with FGR and 80 were healthy individuals assigned to the control group. The local Ethics Committee approved the study and assigned it certificate number 2011-KAEK-25 2018 / 03-05.

\section{Determination of Groups}

According to the recommendations of the Royal College of Obstetricians and Gynecologists (RCOG) from 2013 for the diagnosis of FGR, pregnant women carrying fetuses with an estimated fetal weight (EFW) $<10$, oligohydramnios, abnormal umbilical artery in Doppler ultrasound (absent end diastolic flow or reverse flow) or an EFW $<3 p$ are diagnosed as having fetuses with FGR.

Obstetric examinations were performed, and the length of pregnancy in weeks was established based on the last menstrual period and confirmed by the first trimester ultrasound examination. The number of weeks of gestation considered in the study was calculated based on the last menstrual period and confirmed based on early ultrasound measurements. Birth weight of the newborns was recorded after delivery.

The EFW calculated by ultrasound of the fetuses carried by healthy women was above the $10^{\text {th }}$ percentile $(n=80)$. Subjects with an EFW below the $10^{\text {th }}$ percentile were included in the study group and diagnosed with intrauterine growth restriction $(n=80)$. A single operator performed color Doppler measurements using a Voluson 730 Pro Color Doppler ultrasonography device. A 3.5 MHz convex probe was used in examinations. We evaluated the systole diastole ratio (S/D) and end diastolic flow in the umbilical artery in Color Doppler.

None of the pregnant women included in our study had a poor obstetric history, maternal or fetal problem. History of multiple pregnancy; chronic disease; infection causing FGR; smoking during pregnancy; use of cannabis or cocaine; and alcohol drinking were not studied.

\section{Collection of Blood Samples}

Blood samples of approximately $5 \mathrm{ml}$ were drawn from study participants at any time of the day to investigate PSG-1 levels. The samples taken from each volunteer participant were stored in biochemistry tubes containing an extra separator gel. After waiting for approximately 20 minutes at room temperature, the samples were centrifuged at $5000 \mathrm{rpm}$ for 5 minutes and kept at -20 degrees. PSG-1 levels were studied with ELISA Awerenes Technology INC, Human Pregnancy Specific Beta 1 Glycoprotein assay kits. Results were reported in $\mathrm{ng} / \mathrm{ml}$. Complete blood count, blood glucose, blood urea nitrogen, creatinine, aminotransferase, and PSG-1 levels were evaluated.

\section{Statistical Evaluation}

Statistical analysis was performed with Statistical Package for the Social Sciences (SPSS) version 22.0. The Kolmogorov-Smirnov test was used to test data distribution normality. We presented descriptive analyses using mean $( \pm S D)$ for normally distributed variables and median (range) for data not following a normal distribution. In data comparisons, Student's t-test was used for normally distributed data and the Mann Whitney $U$ test was used for data not following a normal distribution. Spearman's rank correlation was used to assess the relationships between quantitative data. Univariate logistic regression analysis was applied to determine the variables that might predict FGR. Variables with $p<0.25$ as a result of univariate analysis were included in multivariate analysis. The Backward LR method was used in multivariate analysis. The compatibility of the models with the data was evaluated with the Hosmer and Lemeshow test.

ROC curve analysis was used in the calculation of cutoff values for serum PSG-1 level. All statistical calculations were evaluated at a 95\% confidence interval and significance was attributed to differences with $p<0.05$.

\section{RESULTS}

In this study, $80(50.0 \%)$ of 160 pregnant women were pregnant with fetuses with FGR and 80 (50.0\%) were healthy controls. Frequencies and percentages related to pregnancy outcomes of the participants are described in Table 1.

The mean age of the pregnant women included in the study group was $25.9 \pm 4.7$, while the mean body mass index was 28.4 \pm 4.6 . The mean length of gestation of the pregnant women included in the study was 36.6 23.4 weeks, and the mean birth weight of the babies was $2607.84 \pm 887.83$ grams (Table 1 ). Complete blood count and biochemical parameters of the pregnant women included in the study are given in Table 1.

The mean age of the pregnant women with FGR was higher than that of controls, but the difference was not statistically significant $(p>0.05)$. The FGR group had a lower body mass index on average than the control group, but the difference was not statistically significant $(p>0.05)$ (Table 2).

We evaluated the groups in terms of gravidity and parity. We did not find a statistical difference between the groups $(p>0.05)$. The FGR group had fewer weeks of gestation and newborns with lower birth weight than controls $(p<0.05)$ (Table 2).

We did not find a statistically significant difference in hemoglobin, platelet, BUN, or aminotransferase levels between the groups $(p>0.05)$. The creatinine levels of pregnant women with fetuses with FGR were statistically higher than the levels seen in controls $(p<0.05)$ (Table 2$)$.

The median PSG-1 level of pregnant women with intrauterine growth retardation was lower than that of controls. However, the difference was statistically limited $(0.05<$ $p<0.10$ ) (Table 3 ). We compared PSG-1 values in the FGR group based on umbilical artery Doppler ultrasound findings. In patients with absent end diastolic flow (AEDF) in the umbilical artery, median serum PSG-1 was lower when compared with women without AEDF, although the difference was not statistically significant $(p>0.05)$ (Table 4$)$.

Correlation analysis of the data from pregnant women with FGR found only a moderately significant correlation between age and FGR $(p<0.05)$ (Table 5$)$.

Binominal logistic regression was used to determine the variables that might predict FGR. Univariate and multivariate logistic regression analyses were performed to determine the factors affecting FGR and their respective 


\begin{tabular}{|c|c|}
\hline Pregnancy Results and Laboratory Data & Mean $\pm S D$; Median (Range) \\
\hline Age $(y)$ & $25.87 \pm 4.66$ \\
\hline Body Mass Index $\left(\mathrm{kg} / \mathrm{cm}^{2}\right)$ & $28.40 \pm 4.65$ \\
\hline Gravidity (n) & $2(6)$ \\
\hline Parity (n) & $0(4)$ \\
\hline Abortion (n) & $0(4)$ \\
\hline Gestational Age (w) & $36.67 \pm 3.48$ \\
\hline Birth Weight (kg) & $2607.84 \pm 887.83$ \\
\hline Serum PSG-1 (ng/ml) & $16.51(437.33)$ \\
\hline Hemoglobin $(\mathrm{g} / \mathrm{dL})$ & $11.73 \pm 1.28$ \\
\hline Platelets (103/milliliters) & $232(330)$ \\
\hline Blood Urea Nitrogen (mg/dL) & $8.63 \pm 6.90$ \\
\hline Creatinine $(\mathrm{mg} / \mathrm{dL})$ & $0.64(11.2)$ \\
\hline Aspartate Aminotransferase (AST) (U/L) & $22.08 \pm 8.43$ \\
\hline Alanine Aminotransferase (ALT) (U/L) & $13.68 \pm 7.56$ \\
\hline
\end{tabular}

SD: Standard Deviation. Descriptive analyses were presented using (Mean \pm SD) and Median (range) for normally distributed and non-normally distributed variables, respectively.

Table 2. Comparison of Study Groups by Demographic Features and Laboratory Data $(n=160)$.

\begin{tabular}{|c|c|c|c|}
\hline \multirow{2}{*}{$\begin{array}{l}\text { Demographic Features } \\
\text { and } \\
\text { Laboratory Data }\end{array}$} & $\begin{array}{c}\text { FGR Group } \\
n=80\end{array}$ & $\begin{array}{c}\text { Control Group } \\
n=80\end{array}$ & \multirow{2}{*}{$p$ value } \\
\hline & $\begin{array}{c}\text { Mean } \mathbf{S} \text { SD; Median } \\
\text { (Range) }\end{array}$ & $\begin{array}{c}\text { Mean } \pm \text { SD; Median } \\
\text { (Range) }\end{array}$ & \\
\hline Age * & $26.21 \pm 4.83$ & $25.53 \pm 4.50$ & 0.353 \\
\hline Body Mass Index * & $28.07 \pm 5.29$ & $28.73 \pm 3.92$ & 0.370 \\
\hline Gravidity $\beta$ & $2(6)$ & $2(5)$ & 0.947 \\
\hline Parity $\beta$ & $0(3)$ & $0(4)$ & 0.646 \\
\hline Abortion $\beta$ & $0(4)$ & $2(2)$ & 0.391 \\
\hline Gestational Week * & $34.59 \pm 3.58$ & $38.75 \pm 1.65$ & $<0.001$ \\
\hline Birth Weight (grams) $*$ & $1907.69 \pm 662.08$ & $3308.00 \pm 394.03$ & $<0.001$ \\
\hline Hemoglobin* (g/dL) & $11.90 \pm 1.18$ & $11.57 \pm 1.36$ & 0.097 \\
\hline Platelets $\beta$ (103/milliliters) & $237(330)$ & $227(282)$ & 0.569 \\
\hline $\mathrm{BUN} *(\mathrm{mg} / \mathrm{dL})$ & $9.60 \pm 9.43$ & $7.67 \pm 2.25$ & 0.077 \\
\hline Creatinine $\beta(\mathrm{mg} / \mathrm{dL})$ & $0.61(11.2)$ & $0.66(8.41)$ & 0.011 \\
\hline AST* (U/L) & $21.19 \pm 7.78$ & $22.97 \pm 8.99$ & 0.181 \\
\hline $\operatorname{ALT}^{*}(U / L)$ & $14.33 \pm 8.94$ & $13.04 \pm 5.86$ & 0.283 \\
\hline
\end{tabular}

SD: Standard Deviation

* Student $\mathrm{t}$ test used for comparisons between groups

${ }^{\beta}$ Mann Whitney $U$ test used in comparison between groups

odds ratios. The control group was chosen as the reference category.

In the multivariate model created for pregnant women with FGR, birth weight was determined as a predictor of intrauterine growth restriction. As a result, when birth weight increases by one unit, the risk of intrauterine growth retardation decreases by $0.9 \%$ (Table 6 ).

According to logistic regression analysis results, serum PSG-1 did not affect the risk of intrauterine growth retardation in pregnant women ( $p>0.05)$ (Table 6).

As a result of the 'Receiver Operating Characteristic' (ROC) analysis applied for serum PSG-1, the area under the process characteristic curve was calculated as 0.587 and was assigned limited significance $(p=0.058)$. The cutoff value for serum PSG-1 was 12.93 . In cases where serum PSG-1 value with $50 \%$ sensitivity and $76 \%$ specificity was below 12.93, the risk of intrauterine growth retardation was higher (Table 7) (Figure 1).

\section{DISCUSSION}

Intrauterine growth restriction (retardation) occurs when the fetus lags behind the weight it has to reach for its calculated gestational age. The American College of Obstetricians and Gynecologists (ACOG) defines intrauterine 
Table 3. Comparison of Working Groups According to PSG-1 Values.

\begin{tabular}{|l|c|c|c|}
\hline \multirow{2}{*}{$\mathbf{n}=\mathbf{1 6 0}$} & $\begin{array}{c}\text { FGR Group } \\
\mathbf{n = 8 0}\end{array}$ & $\begin{array}{c}\text { Control Group } \\
\mathbf{n = 8 0}\end{array}$ & \multirow{2}{*}{$\boldsymbol{p}$ value } \\
\cline { 2 - 4 } & Median (Range) & Median (Range) \\
\hline Serum Psg $1^{\beta}(\mathrm{ng} / \mathrm{ml})$ & $13.48(328.91)$ & $18.33(437.33)$ & 0.058 \\
\hline
\end{tabular}

SD: Standard Deviation

ß Mann Whitney $U$ test used in comparison between groups

Table 4. Comparison of FGR Groups according to Umbilical Artery Absent End Diastolic Flow in Doppler Ultrasound in terms of PSG1 levels.

\begin{tabular}{|l|c|c|c|}
\hline \multirow{2}{*}{$\mathbf{n = 8 0}$} & $\begin{array}{c}\text { Absent End Diastolic Flow } \\
\mathbf{n = 2 9}\end{array}$ & $\begin{array}{c}\text { Without Absent End Diastolic } \\
\text { Flow } \mathbf{n = 5 1}\end{array}$ & $\boldsymbol{p}$-value \\
\cline { 2 - 4 } & Median (Range) & Median (Range) \\
\hline Serum Psg-1 ${ }^{\beta}(\mathbf{n g} / \mathbf{m l})$ & $12.56(254.5)$ & $14.05(328.91)$ & 0.964 \\
\hline
\end{tabular}

SD: Standard Deviation

${ }^{\beta}$ Mann Whitney $U$ test used in comparison between groups

Table 5. Correlation of PSG1 and Other Parameters in FGR Groups $(n=80)$.

\begin{tabular}{|l|c|}
\hline Parameters & PSG-1 (ng/ ml) \\
\hline \multirow{2}{*}{ Bge } & $\mathrm{r}=-0.328$ \\
\cline { 2 - 2 } & $p=0.003$ \\
\hline \multirow{2}{*}{ Gestational Age } & $\mathrm{r}=-0.123$ \\
\hline Birth Weight & $\mathrm{r}=0.277$ \\
\cline { 2 - 2 } & $p=0.039$ \\
\hline Hemoglobin & $\mathrm{r}=0.009$ \\
\cline { 2 - 2 } & $p=0.934$ \\
\hline Platelets & $\mathrm{r}=-0.013$ \\
\cline { 2 - 2 } & $p=0.908$ \\
\hline Blood Urea Nitrogen & $\mathrm{r}=0.162$ \\
\hline & $p=0.152$ \\
\hline Creatinine & $\mathrm{r}=-0.016$ \\
\hline Aspartate Aminotransferase & $p=0.891$ \\
\cline { 2 - 2 } & $\mathrm{r}=-0.083$ \\
\hline Alanine Aminotransferase & $p=0.464$ \\
\cline { 2 - 2 } & $\mathrm{r}=0.029$ \\
\cline { 2 - 2 } & $p=0.796$ \\
\hline \multirow{2}{*}{ Spearman's rank correlation } & $p=0.812$ \\
\hline
\end{tabular}

r: Spearman's rank correlation coefficient.

BMI: body mass index

growth retardation as having a fetus with an estimated fetal weight below the $10^{\text {th }}$ percentile for its gestational age (ACOG, 2013). We included pregnant women with fetuses with estimated fetal weights below the $10^{\text {th }}$ percentile in our study group.

Compared with fetuses with normal growth, fetuses with FGR are more predisposed to having asphyxia, meconium aspiration, respiratory distress syndrome, massive pulmonary hemorrhage, chronic lung disease, hypothermia, hypoglycemia, hypocalcemia, polycythemia, sepsis, intraventricular hemorrhage, necrotizing enterocolitis, and coagulation abnormalities (ACOG, 2013).

Numerous molecules circulating in maternal peripheral blood during pregnancy are potentially useful markers for pregnancies at risk of FGR. Information about the pathological mechanisms underlying some pregnancy-related diseases has increased significantly. However, most markers are not discriminatory enough to be used clinically and show relatively considerable overlap with levels in pregnant women with average obstetric outcomes (Reis et al., 2002; Page et al., 2002).

Various studies have found that changes in the placental bed have a role in the pathophysiology of FGR (Khong \& Sawyer, 1991; Khong et al., 1986). In cases of intrauterine growth retardation, trophoblast invasion did not occur in the decidua or myometrial layers along some of the spiral arteries.

Pregnancy-specific beta-1-glycoprotein was detected in 1970 by Tatarinov and Masyukevich as a new protein in the serum of pregnant women (Tatarinov \& Masiukevich, 1970; Chou \& Plouzek, 1992). This molecule is a significant pregnancy-associated protein produced by the placenta. It is one of the oncogenic gene products usually examined as a potential marker for the early diagnosis of cancer and effectiveness of cancer therapy. Despite the uses of PSG in the diagnosis of pregnancy and malignancy, this protein's exact physiological role is unknown.

Studies have shown that PSG-1 belongs to a widely purified family of proteins secreted from placental syncytiotrophoblasts from the $2^{\text {nd }}$ week of pregnancy (Teglund et al., 1994). Human placental lactogen (HPL), PSG-1, and alpha-fetoprotein(AFP) values in imminent abortion prediction were investigated in a study performed by Hertz \& Schultz-Larsen (1983). Low PSG-1 values were a better predictor of abortion than HPL and AFP. In another study, the serum PSG-1 levels of 82 healthy pregnant women were compared to the levels seen in 37 women with preeclampsia, eight with fetuses small for gestational age (SGA), and 13 with fetuses with acute fetal distress in the 3rd trimester, revealing that serum PSG-1 levels were lower in women with complicated pregnancies (Silver et al., 1993). We conclude from the study by Sterzik et al. (1989) that serum PSG-1 might be an alternative parameter to beta-hCG as a test to predict and evaluate early ectopic gestation. The literature mentioned above indicates that abnormal serum PSG-1 levels may be a determining factor in pregnancy complications. 


\begin{tabular}{|c|c|c|c|c|c|c|c|c|}
\hline & \multicolumn{4}{|c|}{ Univariate Analysis Results } & \multicolumn{4}{|c|}{ Multivariate Analysis Results } \\
\hline & Wald & OR & CI & $\boldsymbol{p}$ & Wald & OR & CI & $\boldsymbol{p}$ \\
\hline Age & 0.871 & 1.032 & $0.965-1.104$ & 0.351 & & & & \\
\hline BMI & .811 & 0.969 & $0.906-1.037$ & 0.368 & & & & \\
\hline Gestational Age & 36.35 & 0.443 & $0.340-0.578$ & $<0.001$ & & & & \\
\hline Birth Weight & 18.78 & 0.991 & $0.986-0.995$ & $<0.001$ & 18.87 & 0.991 & $0.986-0.995$ & $<0.001$ \\
\hline Psg-1 & 0.965 & 0.998 & $0.995-1.002$ & 0.326 & & & & \\
\hline Hemoglobin & 2.729 & 1.233 & $0.962-1.582$ & 0.099 & & & & \\
\hline Platelets & 0.152 & 1.000 & $1.000-1.000$ & 0.697 & & & & \\
\hline Blood Urea Nitrogen & 4.789 & 1.149 & $1.015-1.301$ & 0.029 & & & & \\
\hline Creatinine & 0.285 & 1.069 & $0.837-1.365$ & 0.593 & & & & \\
\hline $\begin{array}{l}\text { Aspartate } \\
\text { Aminotransferase }\end{array}$ & 1.725 & 0.974 & $0.936-1.013$ & 0.189 & & & & \\
\hline $\begin{array}{l}\text { Alanine } \\
\text { Aminotransferase }\end{array}$ & 1.100 & 1.025 & $0.979-1.072$ & 0.294 & & & & \\
\hline
\end{tabular}

GA (95\%); BMI: body mass index; OR: odds ratio; CI: confidence interval; Wald: test statistic value.

Since the dependent variable consists of 2 groups, binominal logistic regression was used. Control group taken as reference category. As a result of univariate analysis, variables with $p<0.25$ were included in multivariate analysis. Backward LR was used in multivariate analysis. Hosmer and Lemeshow test $p>0.05$ was out, and the models had good data compatibility.

Table 7. Roc Analysis for Serum PSG-1 in FGR Group.

\begin{tabular}{|l|c|c|c|c|}
\hline Area Under the ROC Curve $(95 \% \mathrm{CI})$ & $p$ & Cut-off & Sensitivity & Specificity \\
\hline $0.587(0.498-0.676)$ & 0.058 & 12.93 & 0.50 & 0.76 \\
\hline
\end{tabular}

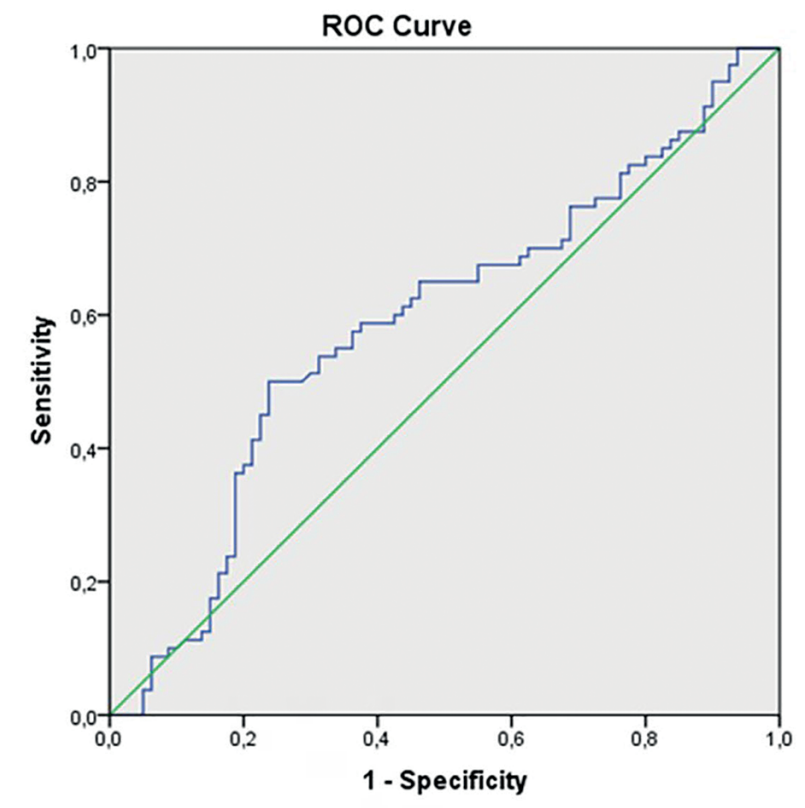

Figure 1. ROC Curve for Serum PSG-1 in Pregnant Women with Fetuses with Intrauterine Growth Restriction.

Our study included 160 volunteers, 80 diagnosed with FGR without any other disease over 24 weeks, and another 80 healthy pregnant women with healthy fetuses. The women with fetuses with FGR had lower serum PSG-1 levels than the healthy pregnant women $(48.16 \pm 77.46 \mathrm{ng} /$ $\mathrm{ml}$ and $62.39 \pm 103.00 \mathrm{ng} / \mathrm{ml}$ ). However, the difference between the two groups in terms of serum PSG-1 levels was not statistically significant $(p=0.058)$.

Examination of the umbilical artery with Doppler ultrasound was performed in 80 patients in the FGR group. The patients were further divided into two groups, one with 29 patients with absent end diastolic flow in umbilical artery Doppler ultrasound at the time of diagnosis and 51 with normal umbilical artery Doppler ultrasound findings. Serum PSG-1 values were lower in the group with absent end diastolic flow (43.86 \pm 66.39 vs. $50.60 \pm 83.63)$. However, the difference was not statistically significant $(p=0.964)$.

Patient demographic characteristics showed the groups were not statistically different in terms of age, gravity, parity, and body mass index. However, the subjects in the FGR group without disorders in Doppler ultrasound examination had a moderately significant correlation between PSG-1, age, and body mass index $(p<0.05)$. The two groups were statistically different in terms of weeks of gestation and birth weight $(p<0.001)$.

Our study did not find a linear relationship between FGR and PSG-1 levels, but PSG-1 values were lower on average in pregnant women diagnosed with FGR. Likewise, pregnant women with fetuses with FGR and absent end diastolic flow had lower PSG-1 levels than their counterparts with normal Doppler ultrasound findings, although the difference was not statistically significant. This is possibly due to the limited number of participants.

The patients included in the study were in the third trimester or pregnancy. Interestingly, serum PSG-1 levels in the early weeks of pregnancy appear to be more useful in predicting FGR. A scoring system combining other molecules and findings associated with FGR should also 
be considered. Maybe PSG-1 should be examined in early-onset severe FGR cases in other studies. We believe that assessing PSG-1 levels may be meaningful, especially in patients with fetuses with FGR and disorders in Doppler ultrasound examination.

Prospective studies looking into early trimester pregnancies, including isolated small-for-gestational-age babies, and evaluating newborn postpartum findings should also be considered. In addition to affecting morbidity and mortality, FGR must be followed because of the significant care costs it may produce. For this reason, diagnostic and therapeutic studies are still ongoing. Further studies on FGR are needed since a biochemical marker to diagnose and regulate the condition has not been found.

\section{CONCLUSION}

In conclusion, the measurement of maternal PSG1 levels may provide clinical information and serve as a predictor of fetal disorders associated mainly with placental problems. Maternal serum PSG-1 levels were lower in women with fetuses with FGR than in healthy pregnant women. Further studies were needed to uncover the role of PSG-1 and other placental proteins.

\section{Authors' participation}

Tuzluoğlu conceived the study, developed it, and wrote the manuscript. Üstünyurt presented the concept of the study and helped write the study. Karaşin performed the computations and supported Tuzluoğlu. Toksoy Karaşin supervised the findings of the study. All authors discussed the results and contributed to the final manuscript. All authors read and approved the final version of the manuscript.

\section{CONFLICT OF INTEREST}

Tuzluoğlu, Üstünyurt, Karaşin, and Toksoy Karaşin have no conflict of interest to declare.

\section{Corresponding author:}

Süleyman Serkan Karaşin

Obstetrics and Gynecology

Health Sciences University

Bursa Yüksek İhtisas Training and Research Hospital

Bursa, Turkey

$+905444309550$

E-mail: sskarasin@icloud.com

\section{REFERENCES}

ACOG committee opinion no. 560: Medically indicated late-preterm and early-term deliveries. Obstet Gynecol. 2013;121:908-10. PMID: 23635709 DOI: 10.1097/01. AOG.0000428648.75548.00

Barker DJ. The long-term outcome of retarded fetal growth. Schweiz Med Wochenschr. 1999;129:189-96. PMID: 10081077

Bohn $\mathrm{H}$. [Detection and characterization of pregnancy proteins in the human placenta and their quantitative immunochemical determination in sera from pregnant women]. Arch Gynakol. 1971;210:440-57. German. PMID: 5001318 DOI: $10.1007 / B F 01628222$

Chou JY, Plouzek CA. Pregnancy-specific $\beta 1$-glycoprotein. Semin Reprod Endocrinol. 1992;10:116-26. DOI: $10.1055 / s-2007-1018867$
Clausson B, Gardosi J, Francis A, Cnattingius S. Perinatal outcome in SGA births defined by customised versus population-based birthweight standards. BJOG. 2001;108:830-4. PMID: 11510708 DOI: $10.1111 / j .1471-$ 0528.2001.00205.x

Dubinsky TJ, Sonneborn R. Trouble With the Curve: Pearls and Pitfalls in the Evaluation of Fetal Growth. J Ultrasound Med. 2020;39:1839-46. PMID: 32329929 DOI: 10.1002/ jum. 15293

Grudzinskas JG, Gordon YB, Menabawey M, Lee JN, Wadsworth J, Chard T. Identification of high-risk pregnancy by the routine measurement of pregnancy-specific beta 1-glycoprotein. Am J Obstet Gynecol. 1983;147:10-2. PMID: 6604456 DOI: 10.1016/0002-9378(83)90075-3

Hertz JB, Schultz-Larsen P. Human placental lactogen, pregnancy-specific beta-1-glycoprotein and alpha-fetoprotein in serum in threatened abortion. Int J Gynaecol Obstet. 1983;21:111-7. PMID: 6193015 DOI: 10.1016/00207292(83)90047-4

Khong TY, De Wolf F, Robertson WB, Brosens I. Inadequate maternal vascular response to placentation in pregnancies complicated by pre-eclampsia and by small-for-gestational age infants. Br J Obstet Gynaecol. 1986;93:104959. PMID: 3790464 DOI: 10.1111/j.1471-0528.1986. tb07830.x

Khong TY, Sawyer IH. The human placental bed in health and disease. Reprod Fertil Dev. 1991;3:373-7. PMID: 1957024 DOI: $10.1071 /$ RD 9910373

Lee JN, Grudzinskas JG, Chard T. Circulating levels of pregnancy proteins in early and late pregnancy in relation to placental tissue concentration. $\mathrm{Br}$ J Obstet Gynaecol. 1979;86:888-90. PMID: 315792 DOI: 10.1111/j.14710528.1979.tb10717.x

Lenton EA, Grudzinskas JG, Gordon YB, Chard T, Cooke ID. Pregnancy specific beta 1 glycoprotein and chorionic gonadotrophin in early human pregnancy. Acta Obstet Gynecol Scand. 1981;60:489-92. PMID: 6975550 DOI: $10.3109 / 00016348109155465$

Macara L, Kingdom JC, Kaufmann P, Kohnen G, Hair J, More IA, Lyall F, Greer IA. Structural analysis of placental terminal villi from growth-restricted pregnancies with abnormal umbilical artery Doppler waveforms. Placenta. 1996;17:37-48. PMID: 8710812 DOI: 10.1016/S01434004(05)80642-3

Page NM, Kemp CF, Butlin DJ, Lowry PJ. Placental peptides as markers of gestational disease. Reproduction. 2002;123:487-95. PMID: 11914111 DOI: 10.1530/ rep. 0.1230487

Reis FM, D'Antona D, Petraglia F. Predictive value of hormone measurements in maternal and fetal complications of pregnancy. Endocr Rev. 2002;23:230-57. PMID: 11943744 DOI: $10.1210 /$ edrv.23.2.0459

Resnik R. Intrauterine growth restriction. Obstet Gynecol. 2002;99:490-6. PMID: 11864679 DOI: 10.1016/s00297844(01)01780-x 
Salafia CM, Minior VK, Pezzullo JC, Popek EJ, Rosenkrantz TS, Vintzileos AM. Intrauterine growth restriction in infants of less than thirty-two weeks' gestation: associated placental pathologic features. Am J Obstet Gynecol. 1995;173:1049-57. PMID: 7485292 DOI: 10.1016/00029378(95)91325-4

Say L, Gülmezoglu AM, Hofmeyr GJ. Maternal oxygen administration for suspected impaired fetal growth. Cochrane Database Syst Rev. 2003;1:CD000137. PMID: 12535388 DOI: $10.1002 / 14651858 . C D 000137$

Shively JE, Beatty JD. CEA-related antigens: molecular biology and clinical significance. Crit Rev Oncol Hematol. 1985;2:355-99. PMID: 3886178 DOI: 10.1016/S10408428(85)80008-1

Silver RM, Heyborne KD, Leslie KK. Pregnancy specific beta 1 glycoprotein (SP-1) in maternal serum and amniotic fluid; pre-eclampsia, small for gestational age fetus and fetal distress. Placenta. 1993;14:583-9. PMID: 8290497 DOI: 10.1016/S0143-4004(05)80211-5

Soothill PW, Nicolaides KH, Campbell S. Prenatal asphyxia, hyperlacticaemia, hypoglycaemia, and erythroblastosis in growth retarded fetuses. $\mathrm{Br}$ Med J (Clin Res Ed). 1987;294:1051-3. PMID: 3107690 DOI: 10.1136/ bmj.294.6579.1051
Sterzik K, Rosenbusch B, Benz R. Serum specific protein 1 and beta-human chorionic gonadotropin concentrations in patients with suspected ectopic pregnancies. Int J Gynaecol Obstet. 1989;28:253-6. PMID: 2466708 DOI: 10.1016/0020-7292(89)90726-1

Tamsen L, Johansson SG, Axelsson O. Pregnancy-specific beta 1-glycoprotein (SP1) in serum from women with pregnancies complicated by intrauterine growth retardation. J Perinat Med. 1983;11:19-25. PMID: 6601703 DOI: 10.1515/jpme.1983.11.1.19

Tatarinov IuS, Masiukevich VN. Immunochemical identification of a new beta-1-globulin in the serum of pregnant women. Biull Eksp Biol Med. 1970;69:66-8. PMID: 4098285 DOI: $10.1007 / B F 00788105$

Teglund S, Olsen A, Khan WN, Frängsmyr L, Hammarström S. The pregnancy-specific glycoprotein (PSG) gene cluster on human chromosome 19: fine structure of the 11 PSG genes and identification of 6 new genes forming a third subgroup within the carcinoembryonic antigen (CEA) family. Genomics. 1994;23:669-84. PMID: 7851896 DOI: $10.1006 /$ geno. 1994.1556

Zhou GQ, Baranov V, Zimmermann W, Grunert F, Erhard B, Mincheva-Nilsson L, Hammarström S, Thompson J. Highly specific monoclonal antibody demonstrates that pregnancy-specific glycoprotein (PSG) is limited to syncytiotrophoblast in human early and term placenta. Placenta. 1997;18:491501. PMID: 9290143 DOI: 10.1016/0143-4004(77)90002-9 